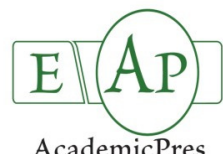

AcademicPres

\title{
Effect of Low Frequency Magnetic Field (LFMF) on the Germination of Seeds and Selected Useful Characters of Onion (Allium cepa L.)
}

\author{
Roman HOŁUBOWICZ ${ }^{1}$, Leszek KUBISZ2*, Marlena GAUZA ${ }^{2}$, Yilin TONG ${ }^{1}$, \\ Dorota HOJAN-JEZIERSKA ${ }^{2}$
}

\author{
${ }^{1}$ Poznań University of Life Sciences, Department of Plant Pathology Seed Science and Technology, Division of Seed Science and Technology, \\ Szamotulska 28, Baranowo 62-081 Przeźmierowo, Poland \\ ${ }^{2}$ Poznań University of Medical Sciences, Department of Biophysics, Poland, Fredry 10, 61-710 Poznań, Poland; \\ lkubisz@ump.edu.pl (*corresponding author)
}

\begin{abstract}
Magnetic fields (MF) have been reported widely as pre-sowing seeds treatment to increase their vigour, seedling growth and the plants' yield. Although, it has been shown that MF could affect seed germination and the seedling root growth, still their further effect on plant's life has been found to be inconsistent, especially under field conditions. Commercial seed lots of onion (Allium cepa L.) of the cultivars 'Octavia' and 'Eureka' were soaked for 12 hours in the distilled water at $20^{\circ} \mathrm{C}$. Next, they were exposed to low frequency magnetic field (LFMF) of magnetic induction B=20 mT, for 10, 30 and 60 minutes. The LFMF was generated using a standard medical device for magnetostimulation VIOFOR JPS. Next, the seeds were evaluated for germination and received bulbs were analysed for the selected useful characters including the root length, maximal diameters, dry matter and quercetin content. For the LFMF treatment of 60 minutes, for the cultivars 'Octavia' and 'Eureka', the energy of germination increased from $75.8 \%$ and $65 \%$ (control) to $88.3 \%$ and $87.5 \%$, respectively. For the LFMF treatment of 60 minutes, the germination capacity, for the same cultivars, increased from $85 \%$ and $76.3 \%$ (control) to $92 \%$ and $90 \%$, respectively, Treated for 60 minutes with LFMF onion seeds had longer seedlings than the ones from the control seeds. These values, for both cultivars, increased from $5.3 \mathrm{~cm}$ and $4.2 \mathrm{~cm}$ (control) to $8.4 \mathrm{~cm}$ and $5.7 \mathrm{~cm}$, respectively. LFMF used for 60 minutes on the 'Octavia' onion seeds, increased their emergences in the field and length of the roots on the bulbs. LFMF used had no effect on the dry matter of bulbs grown out from the seeds when exposing them for 10 and 30 minutes. However, when exposing them for 60 minutes, LFMF decreased the dry matter and increased the amount of quercetin.
\end{abstract}

Keywords: seed germination, seed quality, magnetic field, seed grading

\section{Introduction}

Magnetic fields (MF) have been used widely as presowing seed treatments to increase their vigour, seedling growth and yield (Pietruszewski, 1993, Phirke et al., 1996a, Ahmet, 2003).

Experimental data demonstrate various effects of MF on plants both in vivo (Kavi, 1977, Lebedev et al., 1977, Garcia and Arza, 2001, Flórez et al., 2007, Ahmad and Azita, 2009) and in vitro (Van et al., 2011). There is also no doubt that MF can affect seed germination, root growth and their faster early growth. Still their further effect on plant's life is inconsistent, especially under field conditions (Phirke $e t$ al., $1996 \mathrm{a}, \mathrm{b})$. As a result, there is still the necessity to carry out this kind of research.

In 2000, the world's production of onion was about 46.7 million tons of bulbs from 2.7 million hectares. According to the available FAO data, onion is now the third most important vegetable (after tomato and cabbage) produced in the world. For many years, it has also been the most important fresh vegetable exported from Poland. Its seeds are quite expensive as they lose their germination capacity quickly (Black et al., 2006). This causes huge loss to seed companies all over the world. Therefore, for many years, there has been a search for simple and cheap method to improve germination of onion and other agricultural and horticultural crops seeds (George, 1985, Halmer, 2008).

So far, onion seed production has been investigated, but only one experiment on the effect of MF on onion seed quality has been reported (Tkalec et al., 2009). In their experiments, the MF had no effect on germination of onion seeds. Moreover, it negatively affected radicle cells division.

Previous work on onion seeds (Kubisz et al., 2012) has shown that low frequency magnetic field (LFMF) had a positive effect on germination of onion seeds. 
The main objectives of the study were to confirm the earlier data about the positive effect of LFMF on the onion germination and to find out if LFMF also affects the onion seedlings' total length and selected plant characters of the bulbs received from the seeds treated with this factor.

\section{Materials and methods}

Onion seeds (Allium cepa L.) of two cultivars were used in these experiments: 'Octavia', which came from a Polish seed company "Torseed SA", located in Torun, with the seed lot number PL 804/63/51/002A; and the cultivar 'Eureka', which came from a Polish seed company "CNOS Ożarów Mazowiecki SA - division", "CNOS Poznan', with the seed lot number PL 830/64/13135/408A. Both cultivars are commonly used in professional production in large horticultural farms in Poland. Their seed quality met the actual market quality standards.

First, 1600 full, not damaged and well ripen seeds were selected from each cultivar. Then, they were divided into 4 groups; each treatment had $400(4 \times 100)$ seeds. Before starting the experiment, the seeds were disinfected by soaking them in the 3\% hydrogen peroxide solution for 5 minutes. Then, they were rinsed with sterilized water 3 times and dried out by putting them on the blotting paper.

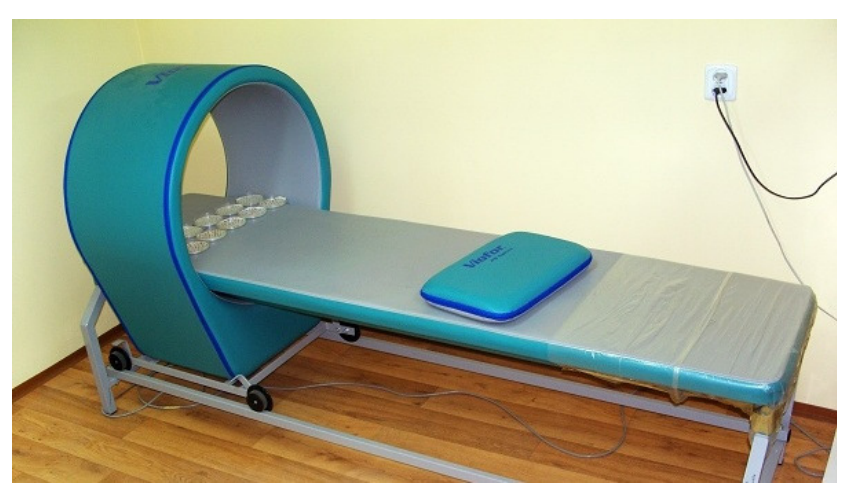

Fig. 1. The Petri dishes with the onion seeds exposed to LFMF generated by the VIOFOR JPS System

After that, they were soaked in the distilled water for 12 hours, and kept in the Elkon CL65 (800W, 220V) thermostat at $20 \pm 1{ }^{\circ} \mathrm{C}$. Next, they were drained, surface dried and placed on the blotting paper in Petri dishes. The seeds were then exposed to LFMF $(20 \mathrm{mT})$ using the VIOFOR JPS System for 10, 30 and 60 minutes. The MF was generated using a standard device for magnetic stimulation VIOFOR JPS applied in human medical treatment using application mode M1 (10 minutes) for 1, 3 or 6 times, programme P1 and filed intensity 12 (Fig. 1).

The parameters of the magnetic field used in the experiment were the same as described previously (Kubisz et al., 2012).

After exposing seeds to LFMF, they were tested for germination following the instructions published by the International Seed Testing Association (ISTA) (Anonymous, 2003). The first counting of seedlings took place after 6 days, and the second one after 12 days.

In the second experiment where the total length of the seedlings was measured, the seeds were treated with the magnetic field in this same manner. After exposition to magnetic field, the seeds were placed onto the wet paper towels, which were then rolled up and tied up on both ends. Next, they were placed in upright position into vessels with distilled water and placed into the thermostat at $20 \pm 1{ }^{\circ} \mathrm{C}$. After 12 days of each treatment, $240(4 \times 60)$ germinating seedlings were taken out. Their total length was measured using a ruler.

In a separate experiment, seeds of the cultivar 'Octavia' were treated the same way and were sown in the field at the Marcelin Experiment Station on June 23 ${ }^{\text {rd }}, 2011$. For each seed treatment, there were 4 replications of 100 seeds sown in 4 rows on the field plot of $1.5 \mathrm{~m} \times 1 \mathrm{~m}$. The conditions of the seeds sowing in the field were as in routine production of the species by onion growers. After sowing the seeds, the field was then watered triweekly. The seeds were sown in the lessive soil created from clay on strong sands, useful to grow sugar beet or wheat, with $\mathrm{pH}=6.5$. On July $15^{\text {th }}$, the counting of the seedlings emergences was done. No plant protection against diseases and pests was used. Plants were collected on October $15^{\text {th }}, 2011,20$ ( 5 for each treatment) and best plants were selected. They were weighed and the root length and the diameter of their bulbs were measured. The bulbs were then taken to the laboratory at the Faculty of Food Science and Nutrition for chemical analyses.

The dry matter was measured directly after harvesting the plants from the field for the bulbs of the cultivar 'Octavia'. The used method has been described by Drzazga (1999), i.e. $0.5 \mathrm{~g}$ onion samples were taken and dried at $130 \pm 1{ }^{\circ} \mathrm{C}$ for 1 hour in automatic analyzer of dry matter OX-35 (ONYX, Fawag. S.A).

The quercetin content was measured using high pressure liquid chromatography (HPLC) method. First, the extraction of the onion samples was made following the method described by Hertog et al. (1992) and Nutilla et al. (2002) with slight modification when it came to hydrolysis. The extraction process was carried out using $70 \%$ solution of acetone employing a single extraction of poly phenols from the examined samples. Acid hydrolysis of $0.5 \mathrm{~g}$ of onion tissue was carried out in round bottom flask with 1.2 N HCL for 2 hours at $90 \pm 1^{\circ} \mathrm{C}$. After cooling, the solution was filtered and centrifuged. The quercetin content was analyzed using the HPLC separation technique and was carried out using the $\mathrm{X}$-Terra $\mathrm{C} 18$ (Waters Corporation, Taunton, MA, USA) column ( $3.9 \mathrm{~L} 150 \mathrm{~mm}, 4 \mathrm{~mm})$. The column was placed in a column oven set at $30 \pm 1{ }^{\circ} \mathrm{C}$. The mobile phase consisted of a mixture of methanol - $4.5 \%$ formic acid water with flow rate of $1 \mathrm{ml} / \mathrm{min}$, by 75 minutes. Then, the samples were injected using autoinjector with a fixed $10 \mathrm{ml}$ loop. The eluted fractions were monitored by UV-VIS 966 detector (Waters Corporation, Taunton, MA, USA). Standards of the analyzed quercetin (Sigma) were used for the identification procedure and the values were recorded in $\mathrm{mg} / \mathrm{g}$ of dry matter.

\section{Statistical analysis}

The received data was subjected to statistic analysis based on the variance calculated and the significant differences were calculated based on the Duncan's test for $\alpha=$ 0.05 . Means followed for a given cultivar and character by 
170

the same letters are not significantly different according to the Duncan's test for $\alpha=0.05$. For some data, standard deviation (SD) was calculated.

\section{Results and discussion}

Weather conditions in the field during the experiment were measured using the station's equipment. The mean air day temperature during the field experiment in June was

Tab. 1. The average day air temperature $\left({ }^{\circ} \mathrm{C}\right)$ and month sums of precipitation $(\mathrm{mm})$ in Poznań at the Marcelin Experiment Station in 2011 and the mean values of the same parameter for the years 2005-2010

\begin{tabular}{ccccc}
\hline Month & \multicolumn{2}{c}{$\begin{array}{c}\text { Average day air } \\
\text { temperature }\end{array}$} & \multicolumn{2}{c}{ Sums of precipitation } \\
& 2011 & $2005-2010$ & 2011 & $2005-2010$ \\
\hline June & 18.7 & 14.7 & 55.0 & 38.6 \\
July & 16.7 & 20.6 & 146.4 & 64.5 \\
August & 18.8 & 18.4 & 30.0 & 62.2 \\
September & 15.1 & 14.8 & 17.4 & 33.3 \\
October & 8.8 & 8.9 & 20.6 & 26.0 \\
\hline
\end{tabular}

higher than the average value for the previous 6 years. However, it was lower for July 2011 which was quite cold and plants grew slower than usually. However, the plant's growth sped up in the late summer and autumn (August and September) because of temperatures higher than usually. Month sums of the rains during the field experiment in June and July were much higher than in the previous years. However, in August, September and October, they were obviously lower than the values at the same time in the years 2005-2010 (Tab. 1).
The LFMF used, increased germination of the tested onion seeds (Tab. 2). For the energy of germination, for the LFMF treatment of 60 minutes, for the cultivars 'Octavia' and 'Eureka', it increased from $75.8 \%$ and $65 \%$ (control) to $88.3 \%$ and $87.5 \%$, respectively. For the 60 minutes treatments, for the same cultivars, the germination capacity increased from $85 \%$ and $76.3 \%$ (control) to $92 \%$ and $90 \%$, respectively. These phenomena were accompanied by changes in the length of seedlings. Onion seeds treated for 60 minutes with LFMF had longer seedlings. Their length increased from $5.3 \mathrm{~cm}$ and $4.2 \mathrm{~cm}$ (control) to $8.4 \mathrm{~cm}$ and $5.7 \mathrm{~cm}$, respectively.

The LFMF used, increased the field emergences of the seeds of the onion cultivar 'Octavia' (Tab. 2). Especially for the 60 minutes treated seeds, there were differences in comparison with the control seeds. For the 10 and 30 minutes treatments, no differences between the treated seeds and the control ones, in terms of their field emergences, were found. Seeds treated with LFMF for 60 minutes grew out eventually in visually better plants (Fig. 2).

The LFMF used on the onion 'Octavia' seeds had no effect on the dry matter of the 3-month-old bulbs grown out from these seeds when exposed for 10 and 30 minutes (Tab. 3), but when treated for 60 minutes, the dry matter decreased and increased the plant's fresh weight, root length maximal diameters of the bulb and its quercetin content.

The numerous experiments, carried out in the last 80 years, have proven in majority of cases, that MF could increase germination of the seeds (Savostin, 1930; Phirke et al., $1996 \mathrm{~b}$ ). The 60 minutes exposition to the $20 \mathrm{mT}$ of LFMF used in this experiment for onion seeds of the cultivars 'Octavia' and 'Eureka', prior the exposition soaked in the distilled water at $20 \pm 1{ }^{\circ} \mathrm{C}$ for 12 hours, resulted in the increase of their germination. These results, however,

Tab. 2. The effect of treating the onion 'Octavia' and 'Eureka' seeds with low frequency magnetic field (LFMF) on their germination energy (\%) and capacity (\%), length of the seedlings (cm) in the laboratory test and field emergences (\%)

\begin{tabular}{cccccc}
\hline Cultivars & Treatment & $\begin{array}{c}\text { Germination } \\
\text { energy }\end{array}$ & $\begin{array}{c}\text { Germination } \\
\text { capacity }\end{array}$ & $\begin{array}{c}\text { Length of the } \\
\text { seedlings }\end{array}$ & $\begin{array}{c}\text { Field } \\
\text { emergences }\end{array}$ \\
\hline 'Octavia' & Control & $75.8^{\mathrm{a}}$ & $85.0^{\mathrm{a}}$ & $5.3^{\mathrm{a}}$ & $10.3^{\mathrm{a}}$ \\
& $10 \mathrm{~min}$. & $80.8^{\mathrm{ab}}$ & $87.5^{\mathrm{ab}}$ & $6.6^{\mathrm{b}}$ & $11.3^{\mathrm{a}}$ \\
& $30 \mathrm{~min}$. & $83.0^{\mathrm{ab}}$ & $88.5^{\mathrm{ab}}$ & $7.5^{\mathrm{c}}$ & $10.8^{\mathrm{a}}$ \\
& $60 \mathrm{~min}$. & $88.3^{\mathrm{b}}$ & $92.0^{\mathrm{b}}$ & $8.4^{\mathrm{d}}$ & $16.3^{\mathrm{b}}$ \\
& 'Eureka' & $60 n+0^{\mathrm{a}}$ & $76.3^{\mathrm{a}}$ & $4.2^{\mathrm{a}}$ & - \\
& $10 \mathrm{~min}$. & $72.5^{\mathrm{b}}$ & $84.8^{\mathrm{b}}$ & $5.1^{\mathrm{b}}$ & - \\
& $30 \mathrm{~min}$. & $80.0^{\mathrm{c}}$ & $85.8^{\mathrm{b}}$ & $5.5^{\mathrm{b}}$ & - \\
\hline
\end{tabular}

${ }^{*}$ Means followed for a given cultivar and character by the same letters are not significantly different according to the Duncan's test for $\alpha=0.05$

Tab. 3. The effect of treating the onion 'Octavia' seeds with low frequency magnetic field (LFMF) on the plant's fresh weight (g), the bulb's root length $(\mathrm{cm})$, the bulb's maximal diameter $(\mathrm{cm})$, the bulb's dry matter $(\%)$, and the quercetin content (mg/g dry matter) in the bulbs grown out from these seeds

\begin{tabular}{|c|c|c|c|c|c|}
\hline Treatment & $\begin{array}{c}\text { Plant's fresh } \\
\text { weight }\end{array}$ & $\begin{array}{l}\text { Bulb's root } \\
\text { length }\end{array}$ & $\begin{array}{c}\text { Bulb's maximal } \\
\text { diameter }\end{array}$ & $\begin{array}{c}\text { Bulb's dry matter } \\
\text { content }\end{array}$ & $\begin{array}{c}\text { Bulb's quercetin } \\
\text { content }\end{array}$ \\
\hline Control & $79.8^{\text {a* }}$ & $13.3^{a}$ & $3.86^{\mathrm{ab}}$ & $16.06^{\mathrm{b}}$ & $4.58 \pm 0.11^{* *}$ \\
\hline 10 minutes & $88.7^{a b}$ & $14.2^{\mathrm{ab}}$ & $3.72^{a}$ & $14.93^{a b}$ & $5.29 \pm 0.09$ \\
\hline 30 minutes & $79.8^{a}$ & $15.3^{b}$ & $4.12^{b c}$ & $15.23^{b}$ & $4.60 \pm 0.11$ \\
\hline 60 minutes & $97.0^{\mathrm{b}}$ & $17.2^{c}$ & $4.21^{c}$ & $12.52^{\mathrm{a}}$ & $6.56 \pm 0.12$ \\
\hline
\end{tabular}

${ }^{*}$ See Tab. 2 for the explanation; ${ }^{* *}$ Standard deviation. 

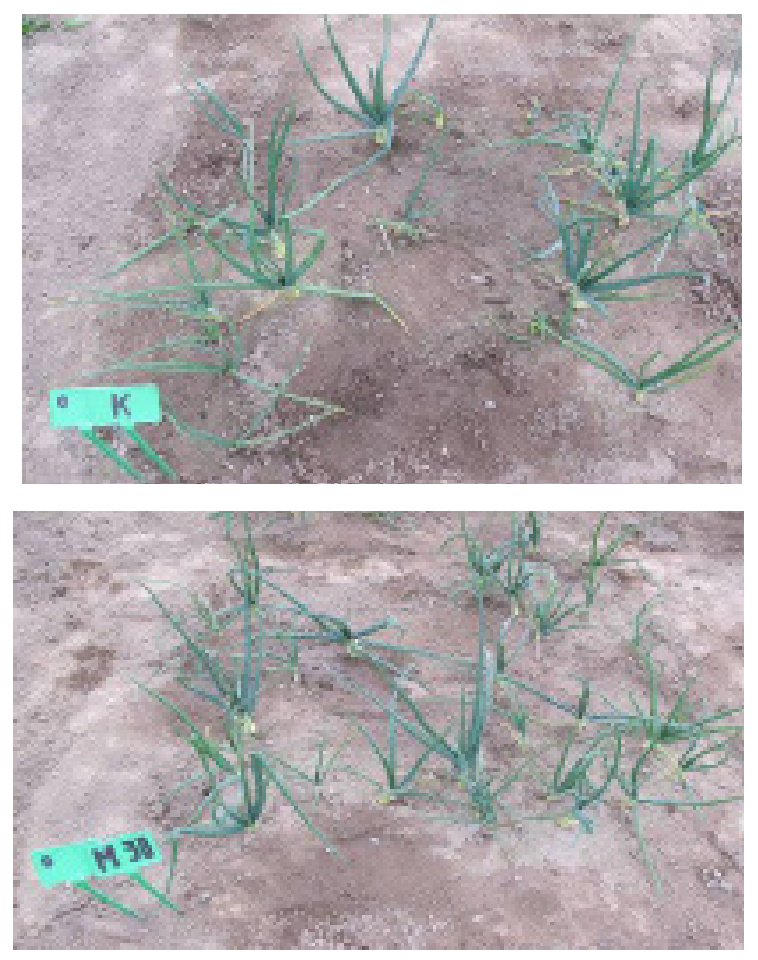
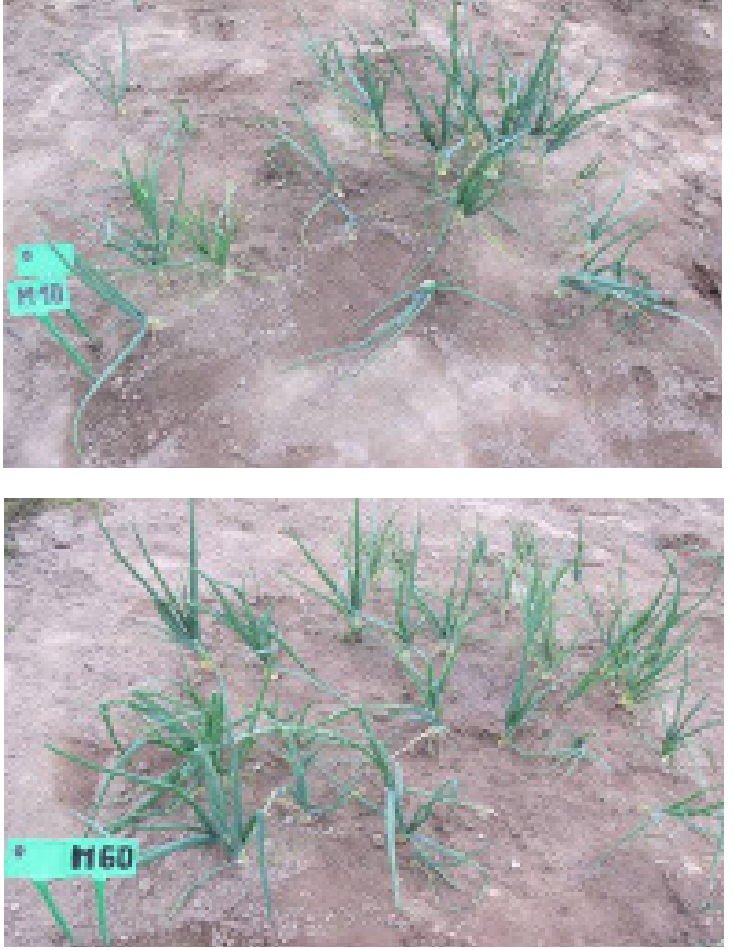

Fig. 2. The effect of low-frequency magnetic field (LFMF) treatment on the field emergences of the onion seeds of the cultivar 'Octavia'. Pictures were taken on October 15th, 2011, at the Marcelin Experiment Station. Abbreviations: K - control, M 10 LFMF for 10 minutes, M 30 - LFMF for 30 minutes, M 60 - LFMF for 60 minutes

depended in high extent on the used cultivar and were not always completely the same, i.e. they varied. The LFMF treated seeds were better germinating and had longer seedlings than the control seeds. This, however, was not always observed due to big variation in the received results (Kubisz et al., 2012). This disadvantage of the MF, as a factor of plant growth, was also reported by Phirke et al. (1996 a, b). For the same reason, there was probably no positive effect of MF on onion seeds germination in the works of Tkelec et al. (2009).

There is no doubt, that seeds of important horticultural crops, such as tomato or onion, will be a subject of research by seed companies to improve their quality and storability. Even if such research with the MF has been done, no data is available today as to their subsequent useful characters in the field. In this aspect, the results obtained by the authors are new and unique. To the best of the authors' knowledge, no data is available in the literature on this subject.

The LFMF used on the onion 'Octavia' seeds decreased the bulbs dry matter content when treated for 60 minutes and increased the plant's fresh weight, root length, maximal diameter and its quercetin content. The LFMF used on the 'Octavia' onion seeds, for the treatment 10 and 30 minutes, had no effect on the dry matter of the bulbs grown out from the seeds, whereas for the 60 minutes treatment decreased the dry matter. The quercitin content in the bulb has been the crucial useful character for onion breeders because it decides about the taste of the bulb. In turn, dry matter of the bulb plays the same crucial role for the onion bulbs in the processing industry. This result, however, as received with small plots, should be commented on rather carefully and, in our opinion, will need to be verified in a separate, follow up larger plots experiment. The obtained result for the 60 - minutes application of the LFMF is in accordance with previous work carried out on the onion seeds by Kubisz et al. (2102).

A bulb size is a very important characteristic in onion seed production. It is so because, when planting big bulbs, higher number of seed stalks is received and consequently bigger seed yield can be expected (Morozowska and Holubowicz, 2009). Root length, in turn, is a crucial factor in breeding onion cultivars with resistance to drought, i.e. longer the roots the better the onion plant's tolerance to water stress (George, 1985). This direction of breeding has been dominating in many seed companies in the world. Higher amount of quercetin found in the bulbs as a result of the LFMF treatment is a positive effect due to the health promoting influence of this flavonoid on humans.

There is, however, more fundamental question: how does the MF affect the seed germination?

So far, we know that the LFMF could elongate the seedling because MF nanoparticles in a molecular process are an endogenous source of magnetic exposure to living tissues and cells, both in plants and animals.

One of the theories formed by Johnsen and Lohman in 2005 said that all living tissues had special very small parts called "nanoparticles", which are involved in biological reaction to MF exposure. They could be generated from magnetic minerals precipatated in living tissue such as: magnetite $\left(\mathrm{Fe}_{3} \mathrm{O}_{4}\right)$, maghernite $\left(\mathrm{Fe}_{2} \mathrm{O}_{3}\right)$ or greigite $\left(\mathrm{Fe}_{3} \mathrm{~S}_{4}\right)$. The crystals of magnetite called magnetosomes were found in the cell membrane. In 2001, Kishvink et al. (after Binhi, 2004 ) proved the relationship between weak magnetic field (200 nT) and responses of biological material.

Mechanisms of the action on LFMF at the initial stages 
172

of germination of wheat seeds have been discovered experimentally. The effect of LFMF at the stage of release of the enzyme called esterase in the course of swelling of wheat seeds greatly speeds up the release of enzymes from the bound state and also the release of seeds from the dormant stage; later, however, the field effect appreciably decreases (Aksenov et al., 1996).

\section{Conclusions}

The low frequency magnetic field (LFMF) $(20 \mathrm{mT})$ used for 12 hours soaked in the distilled water at $20{ }^{\circ} \mathrm{C}$ onion seeds of the cultivars 'Octavia' and 'Eureka' resulted in increasing their germination. The energy of germination for both cultivars increased from $75.8 \%$ and $65 \%$ (control) to $88.3 \%$ and $87.5 \%$, respectively. For the germination capacity, for the 60 minutes treatment with the LFMF, for the same cultivars, it increased from $85 \%$ and $76.3 \%$ (control) to $92 \%$ and $90 \%$, respectively. These phenomena were accompanied by the increase in the length of seedlings, from $5.3 \mathrm{~cm}$ and $4.2 \mathrm{~cm}$ (control) to $8.4 \mathrm{~cm}$ and $5.7 \mathrm{~cm}$, respectively. The used LFMF increased the field emergences of the seeds of the onion cultivar 'Octavia'. Especially for the 60 minutes treated seeds, there were significant differences in comparison with the control plants. For the 10 and 30 minutes treatments, no differences between the treated seeds and the control ones, in terms of their field emergences, were found. The LFMF used for 60 minutes on the onion 'Octavia' seeds increased their emergences in the field and length of the roots on the bulbs. The LFMF used had no effect on the dry matter of bulbs grown out from the seeds when exposed to 10 and 30 minute treatments, but when exposed to a 60 minute treatment, it decreased the dry matter and increased the amount of quercetin content.

\section{References}

Ahmad M, Azita S (2009). Effect of seed pretreatment by magnetic fields on seed germination and ontogeny growth of agricultural plants. Electromagnetics Res Symp, March $23^{\text {rd }}$. $27^{\text {th }} 1137-1141$.

Ahmet E (2003). Effects of magnetic fields on yield and growth in strawberry 'Camarosa'. Hort Sci Biotech 78:145-147.

Aksenov SI, Bulyechev AA, Gruzina TY, Turovetskii VB (1996). Mechanism of action of a low-frequency magnetic field on the initial stages of germination of wheat seeds. Biophys 41:931937.

Anonymous (2003). International rules for seed testing. International Seed Testing Association (ISTA), Zürich, Switzerland.

Binhi VN (2004). Stochastic dynamics of magnetic nanoparticles and a mechanism of biological orientation in the geomagnetic field. Physics. Bio-Ph. December $27^{\text {th }} 1-8$.

Black M, Bewley JD, Halmer P (2006). The Encyclopedia of Seeds Science, Technology and Uses. CAB International Press, 44.

Drzazga B (1999). Techniques of analysis in the food industry.
WSiP, Warszawa, 48 (in Polish).

Flórez M, Carbónell MV, Martínez E (2007). Exposure of maize seeds to stationary magnetic fields: effects on germination and early growth. Environ Exp Bot 59:68-75.

Garcia RF, Arza PL (2001). Influence of a stationary magnetic field on water relations in lettuce seeds. Part I: theoretical considerations. Bioelectromag 22:589-595.

George RAT (1985). Vegetable Seed Production. Longman, London-New York.

Halmer P (2008). Seed technology and seed enhancement. Proc. 28th Internat Horticultural Congress - S13 "Seed Enhancement and Seedling Production Technology". (Eds. Changhoo Chun and Jungmyung Lee). Acta Hort 771:17-26.

Hertog MGL, Hollman PCH, Venema DP (1992). Optimisation of a quantitative HPLC determination of potentially anticarcinogenic flavonoiuds in vegetables and fruits. Agric Food Chem 40:1591-1598.

Kavi PS (1977). The effect of magnetic treatment of soybean seed on its moisture absorbing capacity. Sci Cult 43:405-406.

Kubisz L, Hołubowicz R, Li H, Gauza M, Hojan-Jezierska D, Jaroszyk P (2012). Effect of low frequency magnetic field (LFMF) on the germination of seeds of onion (Allium cepa L.). Acta Phys Pol 121A:49-53.

Lebedev IS, Litvinenko LG, Shiyan LT (1977). After effect of a permanent magnetic field on photochemical activity of chroloplasts. Sov Plant Physiol 24:394-395.

Morozowska M, Hołubowicz R (2009). Effect of bulbs size on selected morphological characters of seed stalks, seed yield and quality of onion (Allium cepa L.) seeds. Folia Hort 21:27-38.

Nutilla AM, Kammiovrta K, Oksman-Caldentey KM (2002). Comparison of methods for the hydrolysis of flavonoids and phenolic acids from onion and spinach for HPLC analysis. Food Chem 76:519-525.

Phirke PS, Kubde AB, Umbakar SP (1996a). The influence of magnetic field on plant growth. Seed Sci \& Technol 24:375392.

Phirke PS, Patil MN, Umbarkar SP, Dudhe YH (1996b). The application of magnetic treatment to seeds: methods and responses. Seed Sci \& Technol 24:365-373.

Pietruszewski S (1993). Effect of magnetic seed treatment on yields of wheat. Seed Sci \& Technol 21:621-626.

Savostin PV (1930). Magnetic growth relations in plants. Planta 12:327.

Tkalec M, Malarić K, Pavlica M, Pevalek-Kozlina B, VidakovićCifrek Z (2009). Effect of radiofrequency electromagnetic field on seed germination and root meristematic cells of Allium cepa L. Mutation Res 672:76-81.

Van PT, Teixeira Da Silva JA, Ham LH, Tanaka M (2011). The effects of permanent magnetic fields on in vitro growth of Phalaenopsis plantlets. J Hort Sci \& Biotechnol 86:473-478. 